\title{
Aroma volatiles recovered in the water phase of cashew apple (Anacardium occidentale L.) juice during concentration
}

\author{
Karina L Sampaio, ${ }^{\text {a* }}$ Deborah S Garruti, ${ }^{\text {b }}$ Maria Regina B Franco, ${ }^{a}$ \\ Natalia S Janzanttic and Maria Aparecida AP Da Silva ${ }^{a}$
}

\begin{abstract}
BACKGROUND: There is a considerable loss of volatile compounds during the thermal concentration of cashew apple juice, damaging product quality, and as yet there is little research on the subject. Thus the purpose of this research was to identify the aroma volatiles evaporated off from cashew apple juice and recovered in the water phase during concentration of this beverage in an industrial plant. Water phase volatiles were extracted using dichloromethane, concentrated under a nitrogen flow, separated by gas chromatography (GC) and identified by GC-mass spectrometry. In order to determine the contribution of each volatile to the cashew aroma, five trained judges evaluated the GC effluents using the Osme GC-olfactometry technique.

RESULTS: 71 volatiles were identified; of these, 47 were odour active. Alcohols were preferentially recovered in the cashew water phase, notably heptanol, trans-3-hexen-1-ol and 3-methyl-1-butanol, representing 42\% of the total chromatogram area and imparting green grass and fruity aroma notes to the water phase. Esters represented $21 \%$ of the total chromatogram area, especially ethyl 2-hydroxyhexanoate, ethyl trans-2-butenoate and ethyl 2-methylbutanoate, and were responsible for the fruity/cashew-like aroma of the water phase. On the other hand, 3-methylbutanoic and 2-methylbutanoic acids were the volatiles that presented the greatest odour impact in the GC effluents of the water phase.

CONCLUSION: Overall, the results of the present study strongly indicated that further concentration of the esters recovered in the water phase, either by partial distillation or by alternative technologies such as pervaporation, could generate a higher-quality natural cashew apple essence.
\end{abstract}

(c) 2011 Society of Chemical Industry

Keywords: volatile compound; cashew apple; Anacardium occidentale; gas chromatography-mass spectrometry; aroma; water phase

\section{INTRODUCTION}

Thermal processing usually reduces the sensory quality of fruit juices, attributed mainly to: (i) the loss, either by evaporation or degradation, of the volatile compounds responsible for the typical aroma and flavour of the fresh fruit; and/or (ii) the formation of additional odour volatiles that have a negative impact on the aroma and flavour of the juice. ${ }^{1-3}$ In the juice of cashew apple, a pseudo-fruit native to Brazil, which possesses an exotic and pleasant aroma and flavour, the loss of volatile compounds during thermal processing seems to occur to a great extent, as suggested by the studies cited below.

The studies of Macleod and Troconis, ${ }^{4}$ Maciel et al., ${ }^{5}$ Maia et al., ${ }^{6}$ Bicalho et al., ${ }^{7}$ Garruti et al., ${ }^{8}$ Valim et al. ${ }^{9}$ and Cardeal et al. ${ }^{10}$ on cashew apple juice suggest the existence of a considerable difference between the fresh and processed products with respect to their volatile profiles. For instance, while Valim et al. ${ }^{9}$ only found 12 esters in a cashew apple juice reconstituted from a commercial concentrated nectar, a significantly higher number of esters were identified by Maciel et al. ${ }^{5}$ (21 esters), by Bicalho et al. ${ }^{7}$ (27 esters) and by Garruti et al. ${ }^{8}$ (23 esters) in the fresh fruit or its fresh juice. Of the esters identified by Garruti et al. ${ }^{8}$ as important volatiles in the fresh cashew apple aroma and flavour, such as ethyl acetate, methyl butanoate, methyl 3methylbutanoate, ethyl butanoate, ethyl 2-methylbutanoate, ethyl 3-methylbutanoate, methyl 3-methylpentanoate and ethyl trans2-butenoate, only ethyl butanoate, ethyl 2-methylbutanoate and ethyl 3-methylbutanoate were found by Valim et al. ${ }^{9}$ in their reconstituted cashew apple juice. These data strongly suggest that thermal processing leads to a drastic loss of cashew apple aroma volatiles.

To minimize the loss of sensory quality in processed juices, notably in concentrated juices, the food industry recovers the volatile compounds evaporated off from the juice during concentration by partial condensation and distillation, amongst

\footnotetext{
Correspondence to: Karina L Sampaio, Faculty of Food Engineering, University of Campinas, UNICAMP, 13083-862 Campinas, SP, Brazil.

E-mail:karinasampaio@hotmail.com

a Faculty of Food Engineering, University of Campinas, UNICAMP, 13083-862 Campinas, SP, Brazil

b EMBRAPA, CNPAT, 60511-110 Fortaleza, CE, Brazil

c School of Pharmaceutical Science, UNESP, 14801-902 Araraquara, SP, Brazil
} 
other techniques. ${ }^{11}$ The recovered material is a water-volatile mixture weighing from $15 \%{ }^{12}$ to $30 \%{ }^{13,14}$ of the original juice. This mixture is subsequently concentrated to strengths ranging from $1: 100$ to $1: 150$, usually by distillation, generating an aroma concentrate known as the water phase, which is added back to the processed juice to recover its natural aroma and flavour. ${ }^{14,15}$

While the recovery of aroma volatiles evaporated off during the concentration of orange juice is technologically well established, ${ }^{16-18}$ and orange water phases of good quality are currently available, the same cannot be said for several tropical fruit juices and notably for cashew apple juice. In fact, there is a general distrust amongst the Brazilian juice plants with respect to the ability of their cashew apple water phases to recover the natural aroma and flavour in their processed juice.

Optimizing the recovery and concentration of the volatiles lost during juice concentration is not trivial. It requires prior knowledge of which volatiles evaporate from the juice during processing and the importance of each individual aroma to the fresh fruit aroma and flavour. For this reason, research has been carried out to identify the volatile compounds evaporated off and recovered during beverage concentration for several fruits, such as mangoes, pineapples, guavas, ${ }^{19}$ apples, ${ }^{15,20}$ grapes, apricots, peaches, strawberries and mulberries. ${ }^{15}$ This knowledge allows researchers and engineers to explore not only the optimization of traditional recovery methods, but also the combined use of modern alternative technologies such as pervaporation, ${ }^{21-24}$ to recover volatiles lost during juice concentration. Unfortunately, with respect to cashew apple juice, with the exception of the study by Ramteke et al., ${ }^{19}$ there is little published data on the subject.

Hence the purpose of the present research was to identify the volatile compounds evaporated off from the juice and recovered in the water phase during the concentration of cashew apple juice at an industrial level, assessing the aroma significance of each volatile. The study explored the subject under the conditions actually practised by the Brazilian juice plants, generating important information for this economic segment, which currently exports approximately US $\$ 1.3$ billion per year and employs $27 \%$ of the national agricultural workforce. ${ }^{25-27}$ In this context, the cashew apple culture is gaining competitiveness, having grown from 1.1 million tons per year in $2001^{28}$ to 1.7 million tons per year in $2009,{ }^{29}$ and employing about 300000 direct and indirect workers. ${ }^{30}$ Approximately $10 \%$ of the fruit production is processed by the juice industry. ${ }^{30}$

\section{MATERIAL AND METHODS}

\section{Raw material}

Cashew apples cultivated in the State of Ceará, Brazil, were harvested manually, the nuts removed and the fruits carefully placed in $10 \mathrm{~kg}$ perforated plastic boxes and transported to the processing plant. On arrival at the plant, the fruits were weighed and green or damaged fruits discarded. The remaining apples were sanitized by immersion in a $100 \mathrm{ppm}$ free chlorine solution for $20 \mathrm{~min}$ and then rinsed with running water.

\section{Juice extraction and concentration}

The cashew apples were crushed in an expeller press in an atmosphere of steam, to avoid enzymatic activity in the juice. The resulting material was passed through a finisher $(0.8 \mathrm{~mm})$ and then through a line filter to reduce the pulp content, and the juice was transferred to a tank where it was homogenized (101 kPa) and de-aerated $(80 \mathrm{kPa})$. Finally, the beverage was concentrated in a four-stage concentrator (first and second stages using a plate evaporator (APV, London, UK), the third stage using a falling film shell and tube evaporator and the fourth stage using a scraped surface evaporator (Rossi \& Catelli, Parma, Italy). The concentration temperature was $59^{\circ} \mathrm{C}$ under vacuum $(85 \mathrm{kPa})$ to a final value of $45^{\circ}$ Brix.

\section{Recovery of volatiles in the water phase}

The volatile compounds lost by evaporation during concentration of the juice in the first stage were recovered using an aroma recovery equipment (Rossi \& Catelli) and collected in $60 \mathrm{~L}$ plastic containers. The water phase obtained was frozen and stored at $-15^{\circ} \mathrm{C}$ until analysed.

\section{Sensory evaluation of the water phase}

The aroma of the cashew apple water phase was evaluated by a sensory panel of 10 trained judges, all of whom were either students or employees at the Food Engineering Faculty of the University of Campinas (FEA/UNICAMP, São Paulo, Brazil).

For training purposes, each individual received both whole and diluted fresh cashew apple juice at juice: water strengths of $1: 1,1: 2,1: 4,1: 10,1: 20$ and $1: 40$. During training, the samples $(40 \mathrm{~mL})$ were served in opaque wine glasses covered with watch glasses. The subjects were asked to sniff the samples, evaluate the intensity of the fresh cashew apple aroma and grade them on a $9 \mathrm{~cm}$ unstructured scale, anchored at the left and right extremes by the terms 'weak' and 'strong', respectively. The subjects were informed that the $1: 40$ and $1: 1$ dilutions exemplified fresh cashew aromas of weak and strong intensities, respectively. The $1: 10$ and $1: 4$ dilutions exemplified fresh cashew aromas of moderate intensity.

At the end of the training period, a test was performed in which each participant rated the aroma of fresh cashew apple in three samples $(1: 4,1: 10$ and $1: 20$ dilutions of whole cashew juice, respectively) using the above-mentioned scale. The test was repeated three times, with the participants in individual booths with red lighting to mask any possible visual difference amongst the samples.

An analysis of variance (ANOVA) was then carried out for each subject, and the levels of significance $(P)$ for $F_{\text {sample }}$ and $F_{\text {repetition }}$ were computed. Individuals showing high sample discrimination power $\left(P F_{\text {sample }} \leq 0.05\right)$, ability to reproduce their judgments $\left(P F_{\text {repetition }} \geq 0.05\right)$ and good agreement with the other panellists were chosen to be members of the trained sensory panel. ${ }^{31,32}$

Finally, for each judge, a $7 \mu \mathrm{L}$ aliquot of the water phase was transferred to a paper strip (IFF Essences and Fragrances, Taubaté, Brazil), and immediately after solvent evaporation, was submitted to the judge, who rated its intensity of fresh cashew aroma and described additional aromatic notes. Transference of the sample to the paper strip was necessary in order to avoid solvent inhalation by the panellists. The researcher carried out the sample transference and submission to each judge.

\section{Isolation of the volatiles recovered in the water phase}

The volatile compounds present in the water phase were extracted with dichloromethane and concentrated under a nitrogen flow. ${ }^{33}$

To verify if the method was efficient in isolating the odour volatiles from the water phase, $7 \mu \mathrm{L}$ of the isolate was transferred to a paper strip (IFF Essences and Fragrances) and submitted to the trained sensory panel. The judges rated the intensity of the 
cashew aroma on a $9 \mathrm{~cm}$ unstructured scale, and described any additional aromatic notes perceived in the isolate. A statistical test ( $t$-test) was performed to compare the intensity of the fresh fruit aroma present in the water phase to that perceived in the isolate. The frequency with which the judges cited each additional aromatic note was also computed.

\section{Gas chromatographic analysis}

The isolate containing the volatile compounds present in the water phase was analyzed in replicate using a Varian 3600 (Palo Alto, CA, USA) high-resolution gas chromatograph equipped with a flame ionization detector (FID). A DB-Wax (JW Scientific, Folsom, CA, USA) fused-silica capillary column ( $30 \mathrm{~m} \times 0.25 \mathrm{~mm}$, $0.25 \mu \mathrm{m}$ ) was maintained at $35^{\circ} \mathrm{C}$ for $9 \mathrm{~min}$, raised to $80^{\circ} \mathrm{C}$ at $5^{\circ} \mathrm{C} \mathrm{min}-1$, then to $100^{\circ} \mathrm{C}$ at $1^{\circ} \mathrm{C} \mathrm{min}^{-1}$, and finally to $210^{\circ} \mathrm{C}$ at $16^{\circ} \mathrm{C} \mathrm{min}{ }^{-1}$, and maintained at $210^{\circ} \mathrm{C}$ ( $\left.T_{\text {final }}\right)$ for $20 \mathrm{~min}$, giving a total of approximately $65 \mathrm{~min}$ of analysis. The splitless mode injector was maintained at $230^{\circ} \mathrm{C}$ and the FID at $260^{\circ} \mathrm{C}$. Hydrogen was the carrier gas at a linear velocity of $51.5 \mathrm{~cm} \mathrm{~s}^{-1}$. The sample volume injected was $2 \mu \mathrm{L}$. Additionally, a C7-C28 series of straight-chain alkanes (Polyscience $211 \mathrm{C}$ kit, Chicago, IL, USA) were dissolved in dichloromethane, and the solution injected in the gas chromatograph, operating under the same conditions. Thus the retention index of each volatile compound detected by the FID of the gas chromatograph was calculated as recommended by Van Den Dool and Kratz. ${ }^{34}$ The indices helped the identification of the odour volatiles perceived by the sensory panel in the GC effluents.

\section{Gas chromatography-mass spectrometry (GC-MS)}

The volatiles present in the isolate were identified in a Shimadzu 17-A gas chromatograph coupled to a Shimadzu QP-5000 mass spectrometer (Kyoto, Japan), operating under an ionization voltage of $70 \mathrm{eV}$, scan mode and $\mathrm{m} / \mathrm{z}$ range from 35 to 350 . The column and oven conditions were the same as those used for the GC-FID analysis. Helium was the carrier gas, at a linear velocity of $46 \mathrm{~cm} \mathrm{~s}^{-1}$. The injection volume was $3 \mu \mathrm{L}$.

\section{Identification of volatiles}

To help with identification of the volatile compounds, linear retention indices (LRI) were calculated for the GC-MS data and compared with indices reported in the literature. ${ }^{8,9,35,36}$ Thus a C7-C28 series of straight-chain alkanes (Polyscience $211 \mathrm{C}$ kit) were dissolved in dichloromethane, and the solution injected into the gas chromatograph-mass spectrometer, operating under the same conditions described above. The retention index of each compound was calculated as recommended by Van Den Dool and Kratz. $^{34}$

Individual compounds were identified by: (i) comparing the experimentally obtained mass spectra of the compound with those provided by the Wiley and Nist libraries; (ii) comparing the volatile retention index obtained using the DB-Wax column with the retention indices published in the literature for columns with the same polarity; ${ }^{8,9,35,36}$ and (iii) comparing the volatile mass spectra with the mass spectra of pure compounds analysed in the same gas chromatograph-mass spectrometer using the same methodological conditions.

The compounds were considered positively identified if their mass spectra and retention indices were comparable to those of the pure standards analysed under the same conditions. The compounds were considered identified when their mass
Table 1. Mean intensity ${ }^{\mathrm{a}}$ of fresh cashew apple aroma in water phase and related isolate ( $n=10$ judges)

\begin{tabular}{|lc|} 
Sample & $\begin{array}{c}\text { Intensity of cashew apple } \\
\operatorname{aroma}^{\mathrm{a}}( \pm \text { standard deviation })\end{array}$ \\
\hline Water phase & $5.67( \pm 1.94)$ \\
Water phase isolate & $6.46( \pm 2.14)$ \\
$P_{\mathrm{t}-\text { test }}{ }^{\mathrm{s}}$ & 0.09 \\
\hline a $0=$ weak (juice dilution, $1: 40) ; 9=$ strong (juice dilution, $1: 1)$. \\
$\mathrm{b}$ Level of significance in the $t$-test between mean intensity observed \\
in water phase and respective isolate.
\end{tabular}

spectra matched those available in the computerized library and their retention indices were similar to those reported in the literature..$^{8,9,35,36}$ Finally, compounds were considered tentatively identified when their identification was based solely on their mass spectrometric data.

\section{Aroma volatiles in the water phase}

The odour significance of the volatiles present in the water phase was assessed using the Osme GC-olfactometry technique (GC-O). ${ }^{8}$ For this analysis, the Varian 3600 gas chromatograph described above was modified, and the DB-Wax capillary column was moved from the FID detector to another base detector heated at $250^{\circ} \mathrm{C}$. A sniffer, consisting of a $60 \mathrm{~cm} \times 1 \mathrm{~cm}$ silanized glass tube ( $98 \%$ trimethylchlorosilane, Acros Organics, Geel, Belgium) was placed on top of the above-mentioned detector base to direct the GC effluents to the judge's nose. GC effluents leaving the DB-Wax column were mixed with heated $\left(28^{\circ} \mathrm{C}\right)$, humidified charcoal-filtered air $\left(4 \mathrm{~L} \mathrm{~min}^{-1}\right)$ and directed to the judge's nose. The chromatographic conditions were the same as previously described. Five judges from the trained panel participated in the GC-O analysis (three women and two men, ranging from 24 to 38 years old). Using a computer mouse, each judge rated the intensity of each odour perceived in the GC effluent using a 10 -point scale located on the computer monitor ( $0=$ none; 10 = extreme). In addition, the judges described the odour quality of each odorant to the researcher. Time and intensity values were registered and stored using SCDTI software developed at UNICAMP, Campinas, Brazil. The cashew apple water phase was analysed in triplicate by each judge. The judges evaluated the 65 min chromatographic run in two independent sessions of 32.5 min each.

For each judge, after making his/her GC-O analysis, the SCDTI software generated an individual aromagram named an Osmegram. The Osmegram represented the judge's perception of each odorant present in the GC effluent, as a peak similar to those drawn in the chromatogram. For each odour peak, the SCDTI also reported the corresponding maximum intensity, odour duration and area. ${ }^{8}$

A consensus Osmegram was constructed for the water phase isolate, averaging all the peaks detected twice by at least two judges.

\section{RESULTS AND DISCUSSION Water phase sensory attributes}

As shown in Table 1, the aroma note described as 'fresh cashew apple' was present in the water phase at a moderate intensity, demonstrating that volatiles important to this sensory note were 
Table 2. Aroma notes (\% of citations) in addition to that of fresh cashew apple perceived by the sensory panel in the water phase and in its related isolate ( $n=10$ judges)

\begin{tabular}{|lcc|} 
Descriptor & Water phase (\%) & Isolate (\%) \\
\hline Fruity & 25.0 & 35.6 \\
Sweet/candy & 31.2 & 16.9 \\
Floral & 12.5 & 11.8 \\
Strawberry & 12.5 & 3.4 \\
Fermented overripe fruit & 12.5 & 6.8 \\
Woody & 6.2 & 6.8 \\
\hline
\end{tabular}

in fact lost during juice concentration, and recovered in the water phase.

Table 1 also indicates that there was no significant difference $(P=0.09)$ between the water phase and its isolate with respect to their intensity of fresh cashew aroma. This confirms that the volatile compounds responsible for this aroma note in the water phase were successfully isolated.

Finally, Table 2 shows that both the water phase and the isolate presented additional aromatic notes, described by the sensory panel as 'sweet' (or 'candy'), 'fruity', 'floral' 'overripe fruit' and 'wood', most of these descriptors being consistent with odour compounds previously identified in fresh cashew apple juice by the current research group. ${ }^{8}$

\section{Volatiles recovered in the water phase}

The water phase contained 76 volatile compounds, of which 71 were identified, as shown in Table 3. The majority of the volatiles identified in the water phase were esters ( 27 compounds), followed by alcohols (21), acids (11), aldehydes (4), ketones (4), lactones (3) and one hydrocarbon (1).

Alcohols were the volatiles present in the highest proportion in the water phase, representing $42 \%$ of the total area of the chromatogram (Table 3). Esters were the class of compounds present in the second highest proportion in the water phase, representing $21 \%$ of the total area of the chromatogram, followed by acids (13\%), ketones and lactones (13\%).

Of the alcohols, 3-methyl-1-butanol was the major compound, representing $24 \%$ of the total area of the chromatogram (Table 3 ), followed by cis-3-hexen-1-ol (4.5\%) and hexanol (4.1\%).

Ethyl 2-hydroxy-4-methylpentanoate was the most abundant ester found in the water phase. It represented approximately $14 \%$ of the total area of the chromatogram and was followed by ethyl 3-methylbutanoate (3\%) and a series of other esters, such as ethyl 2-methylbutanoate (1\%), ethyl hexanoate and ethyl trans2 -methyl-2-butenoate $(0.7 \%)$, occurring in minor proportions (Table 3).

Two ketones were present in high proportions in the water phase: 3-hydroxy-2-butanone, corresponding to approximately $7 \%$ of the total area of the chromatogram, and 2,3-butanedione (3.3\%) (Table 3). One lactone, $\gamma$-dodecalactone, was present in noticeable amounts (2.1\%). Of the acids, the mixture of 2-methylbutanoic and 3-methylbutanoic acids represented $11.6 \%$ of the total area of the chromatogram, accounting for almost the whole amount of acids present in the water phase. Finally, Table 3 shows that the aldehydes were only minor volatiles in the water phase, trans-2-hexenal being the most abundant (1.5\%).

The number of alcohols identified in the water phase (21) was higher than that reported by most researchers for cashew juice.
Table 3. Volatile compounds identified in the cashew apple water phase and respective area (\%) of the chromatogram

LR

(DB-Wax) Compound $\%$ Area (FID)

20.99

$<1000$

$<1000$

1010

1014

1032

1048

1067

1115

1127

1166

1182

1203

1237

1239

1298

1338

1407

1429

1486

1522

1547

1596

1662

1696

1800

1936

2134

1038

1096

1119

1159

1173

1178

1226

1262

1314

1318

1323

1330

1359

1366

1388

1409

1460

1502

1566

1907

2049

1074

114

1209

1451

Ethyl propanoate ${ }^{\mathrm{b}}$

20.99

Ethyl 2-methylpropanoate ${ }^{b}$

Methyl 2-methylbutanoate ${ }^{b}$

Methyl 3-methylbutanoate ${ }^{a}$

0.16

Ethyl 2-methylbutanoate ${ }^{a}$

0.17

Ethyl 3-methylbutanoate ${ }^{\mathrm{a}}$

0.97

Methyl trans-2-butenoate ${ }^{b}$

3.31

Isoamyl acetate

0.03

Ethyl trans-2-butenoate ${ }^{a}$

0.05

Ethyl 3-methylpentanoate ${ }^{b}$

Methyl 2-ethylacrylate ${ }^{c}$

Ethyl hexanoate ${ }^{a}$

0.04

0.04

$\operatorname{tr}$

Ethyl trans-2-methyl-2-butenoate ${ }^{a}$

Ethyl trans-3-hexenoate ${ }^{b}$

Ethyl trans-2-hexenoate ${ }^{b}$

Ethyl 3-hydroxy-3-methylbutanoate

Ethyl octanoate ${ }^{b}$

Methyl 2-hydroxy-3-methylpentanoate ${ }^{b}$

Methyl 2-hydroxy-4-methylpentanoate ${ }^{c}$

Ethyl 2-hydroxy-4-methylpentanoate ${ }^{b}$

Ethyl 2-hydroxyhexanoate ${ }^{\mathrm{b}}$

Ethyl decanoate ${ }^{b}$

Ethyl 3-hydroxyhexanoate ${ }^{b}$

2-Phenylethyl acetate ${ }^{b}$

3-Phenylpropyl acetate ${ }^{c}$

Ethyl cinnamate ${ }^{\mathrm{b}}$

0.05

0.09

0.24

$\operatorname{tr}$

0.03

0.34

13.97

0.12

$\operatorname{tr}$

0.04

0.08

$\operatorname{tr}$

0.30

Alcohol

2-Methyl-3-buten-2-ol ${ }^{b}$

42.06

0.29

2-Methyl-1-propanol ${ }^{\mathrm{a}}$

1.62

3-Pentanol ${ }^{\text {b }}$

0.05

1-Butanol

1-Penten-3-ol ${ }^{\mathrm{b}}$

0.36

3-Buten-1-ol ${ }^{b}$

0.98

3-Methyl-1-butanol ${ }^{\mathrm{a}}$

0.72

1-Pentanol ${ }^{\mathrm{a}}$

24.03

Trans-2-Penten-1-ol ${ }^{\mathrm{b}}$

4-Methyl-1-pentanol ${ }^{b}$

Cyclopentanol ${ }^{\mathrm{C}}$

3-Methyl-1-pentanol ${ }^{b}$

Hexanol $^{b}$

Trans-3-Hexen-1-ol ${ }^{\mathrm{b}}$

cis-3-Hexen-1-ol ${ }^{\mathrm{a}}$

Trans-2-Hexen-1-ol ${ }^{\mathrm{b}}$

Heptanol $^{\mathrm{b}}$

2-Ethyl-1-hexanol ${ }^{b}$

1-Octanola

Phenylethyl alcohol ${ }^{\text {b }}$

3-Phenyl propanol ${ }^{b}$

Aldehyde

Hexanal $^{a}$

2-Methyl-4-pentenalc

0.95

0.10

0.29

0.91

0.56

4.11

0.94

4.52

0.36

0.14

0.10

0.39

0.45

0.19

1.94

0.11

0.12

Trans-2-Hexenal ${ }^{b}$

1.54

Furaldehyde ${ }^{\mathrm{b}}$

0.17

Ketone/lactone

12.88

$<1000$

2,3-Butanedione ${ }^{\mathrm{b}}$ 
Table 3. (Continued)

LRI

(DB-Wax)

Compound

$\%$ Area (FID)

\begin{tabular}{|c|c|c|}
\hline 1055 & 2,3-Pentanedione ${ }^{b}$ & 0.07 \\
\hline 1282 & 3-Hydroxy-2-butanone ${ }^{a}$ & 7.08 \\
\hline 1628 & Acetophenone $\mathrm{b}^{\mathrm{b}}$ & 0.38 \\
\hline 1721 & $\gamma$-Hexalactone ${ }^{b}$ & $\operatorname{tr}$ \\
\hline 2025 & $\gamma$-Nonalactone ${ }^{b}$ & $\operatorname{tr}$ \\
\hline \multirow[t]{2}{*}{2399} & $\gamma$-Dodecalactone ${ }^{b}$ & 2.05 \\
\hline & Acids & 12.62 \\
\hline 1445 & Acetic acid ${ }^{b}$ & $\operatorname{tr}$ \\
\hline 1566 & 2-Methylpropanoic acid & $\operatorname{tr}$ \\
\hline 1667 & 3-Methylbutanoic acid ${ }^{\mathrm{b}}$ & 11.63 \\
\hline 1667 & 2-Methylbutanoic acid ${ }^{\mathrm{a}}$ & \\
\hline 1846 & Hexanoic acid ${ }^{a}$ & 0.34 \\
\hline 1873 & Benzylic acid ${ }^{b}$ & 0.03 \\
\hline 2058 & Octanoic acid ${ }^{b}$ & 0.27 \\
\hline 2176 & Nonanoic acid ${ }^{b}$ & 0.08 \\
\hline 2271 & Decanoic acid ${ }^{b}$ & 0.27 \\
\hline 2484 & Undecanoic acid ${ }^{\mathrm{b}}$ & $\operatorname{tr}$ \\
\hline \multirow[t]{2}{*}{2560} & Phenylacetic acid ${ }^{b}$ & $\operatorname{tr}$ \\
\hline & Hydrocarbon & 0.11 \\
\hline \multirow[t]{2}{*}{1248} & Benzocyclobutene $e^{c}$ & 0.11 \\
\hline & Unidentified compounds & 5.09 \\
\hline 1379 & $\mathrm{NI}$ & 1.05 \\
\hline 1414 & $\mathrm{NI}$ & $\operatorname{tr}$ \\
\hline 1513 & $\mathrm{NI}$ & 2.85 \\
\hline 1951 & $\mathrm{NI}$ & $\operatorname{tr}$ \\
\hline 2437 & $\mathrm{NI}$ & 1.19 \\
\hline
\end{tabular}

$\mathrm{NI}$, compound not identified; tr, detected in trace amounts $(<0.01 \%)$.

a Compound positively identified (pure standard).

${ }^{b}$ Compound identified by MS and linear retention index.

c Compound tentatively identified.

Macleod and Troconis ${ }^{4}$ identified two alcohols; Maciel et al., ${ }^{5}$ eight; Maia et al., ${ }^{6}$ five; Bicalho et al., ${ }^{7}$ four; Garruti et al., ${ }^{8}$ eight; Valim et al., ${ }^{9}$ two; Cardeal et al., ${ }^{10}$ one; and Carasek and Pawliszyn, ${ }^{37}$ one. Additionally, the proportion of alcohols present in the water phase of the current study ( $42 \%$ of the total area of the chromatogram) was expressively higher than that found in fresh cashew apple juice by Garruti et al., ${ }^{8}$ by Bicalho et al. ${ }^{7}$ and by Macleod and Troconis. ${ }^{4}$ Part of this divergence could be attributed to differences amongst the methodologies used by the mentioned authors to isolate the volatile compounds present in the samples, but part of this difference could also be attributed to a preferential recovery of alcohols in the water phase during juice concentration. In fact, in a study of the recovery of guava volatiles carried out by Jordán et al., ${ }^{38}$ the alcohols present in the water phase represented $65 \%$ of the total volatiles (expressed in $\mathrm{mg}$ volatiles $\mathrm{kg}^{-1}$ essence), while in the fresh purée they only represented $28 \%$ of the total volatiles found in the product (expressed in $\mathrm{mg}$ volatiles $\mathrm{kg}^{-1}$ purée). Similar results were observed in the studies of volatiles recovered during the concentration of passion fruit, ${ }^{39}$ banana ${ }^{40}$ and kiwi juices. ${ }^{41}$ In all the water phases mentioned, the proportion of alcohols almost doubled compared to that present in the fresh juice.

On the other hand, part of the alcohols found in the water phase in the current study may be products of the thermal degradation of other compounds originally present in the fresh cashew apple juice. For instance, Ducruet et al. ${ }^{42}$ reported the formation of several alcohols and acids during the storage of strawberries, including 3-methyl-1-butanol, 1-hexanol and butanoic acid, which the authors regarded as degradation products from esters such as hexyl butanoate and 3-methyl butylbutanoate. In citrus juices, ${ }^{18}$ excess heat treatment can result in the degradation of esters to alcohols and acids, imparting an off-aroma to the sample described as 'wet dog'.

The proportion of esters identified in the current water phase ( $21 \%$ of the total area of the chromatogram), was significantly lower than that reported for fresh cashew apple juice by Garruti et $a .^{8}$ and Bicalho et al. ${ }^{7}$ However, all the major esters present in the current water phase, such as ethyl 3-methylbutanoate (3.3\% of the total area of the chromatogram), ethyl 2-methylbutanoate (1.0\%), and a mixture of ethyl hexanoate and ethyl 2-methyl-2-butenoate $(0.7 \%)$, were also amongst the most abundant esters reported by the above-mentioned authors. For instance, for Garruti et al. ${ }^{8}$ ethyl 3-methylbutanoate was the major ester identified in their sample. Similarly, for Bicalho et al. ${ }^{7}$ ethyl 2-hydroxy-4-methylpentanoate was the major ester found in the fresh cashew juice, followed by ethyl hexanoate and ethyl 2-methyl-2-butenoate. In juice concentration, considering the acidic conditions of the juice, excess heating will result in the breaking down of esters to alcohols and acids. ${ }^{18}$ Further investigations are needed before concluding that these reactions explain the lower proportion of esters and the higher proportion of alcohols identified in the current water phase, as compared with the results reported by other researchers. $4,5,7-10,37$

Acids were present in moderately high proportions in the water phase analysed in the present study, notably 2-methylbutanoic and 3-methylbutanoic acids (11.6\% of the total chromatogram area). However, in most studies carried out with cashew apple juice, acids were minor volatiles. ${ }^{4,5,7-10,37}$

While aldehydes were minor volatile compounds in the water phase analyzed in the present study $(1.9 \%$ of the total chromatogram area), they were reported as major compounds by Garruti et al. ${ }^{8}$ and by Macleod and Troconis ${ }^{4}$ in fresh cashew juice. It is possible that part of this divergence is due to differences amongst the methodologies used by the mentioned authors to isolate the volatile compounds present in the samples. It is also possible, however, that part of the aldehydes evaporated from the juice during the concentration process were not efficiently recovered in the water phase.

The proportion of lactones identified in the present water phase was similar to the values reported by most researchers working with fresh cashew apple juice. ${ }^{5,6-8,10,37}$

\section{Aroma volatiles recovered in the water phase}

The sensory assessment of the water phase chromatographic effluents revealed the presence of 52 odour-active compounds (Fig. 1). Acids were the class of volatiles causing the highest odour impact in the GC effluents, notably the mixture of 3-methylbutanoic and 2-methylbutanoic acids (peaks 44 and 45), described as possessing a 'cheesy' odour, perceived at an average intensity of 9.2 on a 10-point intensity scale, and contributed to $26.7 \%$ of the total area of the water phase aromagram (Table 4). 2-Methylbutanoic acid was also the volatile promoting the highest odour impact in the GC effluents of fresh cashew apple juice analysed by Garruti et al., ${ }^{8}$ and by Valim et al. ${ }^{9}$ in processed cashew apple juice, where it was described as imparting 'overripe fruit' and 'sweaty' notes to the GC effluents. Overall, although acids represented the class of compounds occupying the highest percentage of the total 

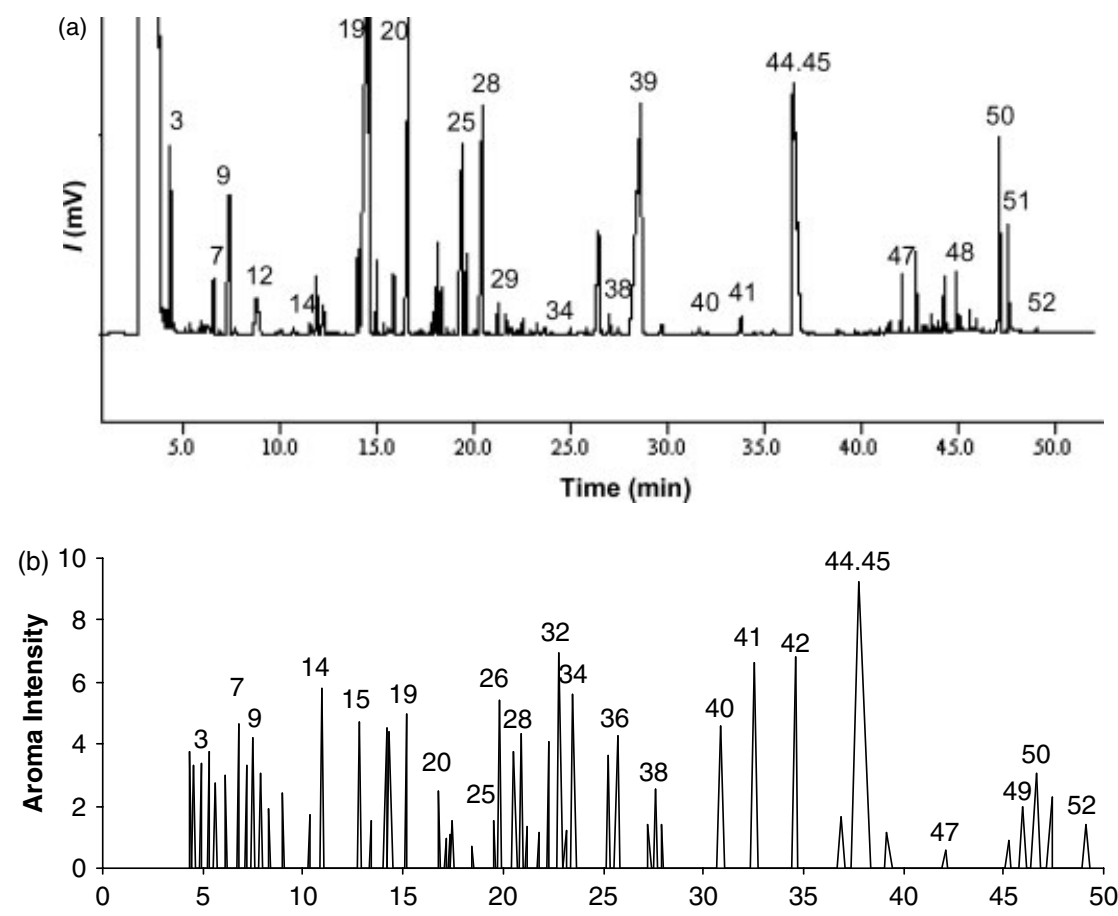

Figure 1. (a) Gas chromatogram and (b) consensus aromagram of cashew water phase isolate showing the positions of some odour-active compounds.

area of the water phase aromagram, this was mostly due to the mixture of 3-methylbutanoic and 2-methylbutanoic acids.

Esters were the second most important class of odour compounds present in the water phase, representing $25 \%$ of the total area of the water phase aromagram, a value inferior but comparable to the $36 \%$ found in the fresh cashew apple ${ }^{8}$ aromagram (Table 4). Most of the esters identified in the water phase isolate were aroma compounds and possessed odour notes described as fruity, sweet and cashew apple-like, notably ethyl 2-hydroxyhexanoate (peak 41), ethyl trans-2-butenoate (peak 15), ethyl 2-methylbutanoate (peak 7), ethyl 3-methylbutanoate (peak 9), methyl 2-ethylacrylate (peak 17) and ethyl octanoate (peak 31). Undoubtedly esters were the most important beneficial contributors to the sensory quality of the water phase, notably to the aroma notes described as fruity, sweet and cashew apple-like. Similarly, esters were the most important volatiles associated with the aroma of fresh cashew apple juice analyzed by Garruti et al. ${ }^{8}$ and by Maciel et al., ${ }^{5}$ notably ethyl butanoate, ethyl 2-methylbutanoate, ethyl 3-methylbutanoate and ethyl trans-2butenoate.

The results shown in Table 4 indicate that after the esters alcohols were the class of compounds that most contributed to the desirable aroma notes perceived by the sensory panel in the water phase. Together, alcohols represented $17.2 \%$ of the total aromagram area, and were mostly associated with aroma notes described as green grass and fruity. Of the odour-active alcohols identified in the water phase, heptanol, trans-3-hexen-1-ol, 3methyl-1-butanol, 1-octanol and 2-ethyl-1-hexanol imparted the highest odour intensity to the GC effluents. In the cashew apple isolate $^{8}$ alcohols represented only $6 \%$ of the total aromagram area, and cis-3-hexenol alone represented $5 \%$ of the total area. In the fresh juice analysed by Garruti et al. ${ }^{8}$ alcohols represented only $5.6 \%$ of the total area of the aromagram, most of this area $(5.1 \%)$ being due to the odour of cis-3-hexen-1-ol.
Finally, aldehydes were the least significant class of aroma volatiles identified in the water phase GC effluents. They represented only $6.4 \%$ of the total aromagram area, and were mostly associated with the odour impact of 2-methyl-4-pentenal and trans-2-hexenal, the former being described as possessing a desirable green grass and fruity aroma note, and the latter mostly associated with undesirable odour notes (Table 4). In the fresh cashew apple juice studied by Garruti et al., ${ }^{8}$ aldehydes showed greater importance as odour volatiles, since they represented $17 \%$ of the total aromagram area, mostly related to the odours of hexanal, 2-methyl-2-pentenal, trans-2-hexenal and octanal.

Of the ketones and lactones, acetophenone and $\gamma$-dodecalactone were the most significant odour compounds perceived in the GC effluents of the water phase. The former was associated with an undesirable aroma described as 'cheesy' and 'waxy', the latter as possessing a 'cashew' and 'herb' aroma. Together, both compounds represented $6.8 \%$ of the total area of the aromagram, suggesting that ketones are not major contributors to the overall aroma of the water phase analysed in the present study. Similar results were reported by Garruti et al. ${ }^{8}$ for fresh cashew apple juice and by Valim et al. ${ }^{9}$ for thermally processed cashew juice.

\section{CONCLUSIONS}

Unlike previous results reported for fresh cashew apple juice and the fruit, 5,7,8 alcohols, and not esters, were the volatiles present in highest proportions in the water phase. However, esters promoted a greater impact in the water phase odour than the alcohols. After the acids, esters were the most important class of odour compounds present in the water phase. The relatively high proportion of alcohols in the water phase, to the detriment of the presence of esters, is certainly an interesting topic for further investigation. Overall, the results of the present study strongly indicate that further concentration of the recovered esters, either by partial distillation or by alternative technologies 


\begin{tabular}{|c|c|c|c|c|c|c|}
\hline Peak & Compound & Freq $^{\text {a }}$ & Descriptor $^{\mathrm{b}}$ & $I_{\max }{ }^{\mathrm{c}}$ & $\% A_{\text {Osme }}{ }^{d}$ & $\% A_{\text {FID }}{ }^{\mathrm{e}}$ \\
\hline & Ester & & & & 24.66 & 19.89 \\
\hline 1 & Ethyl propanoate & 13 & Fruity, sweet, cashew apple & 3.76 & 0.82 & 0.12 \\
\hline 2 & Ethyl 2-methylpropanoate & 10 & Fruity, sweet, cashew apple & 3.29 & 1.17 & 0.16 \\
\hline 4 & Methyl 3-methylbutanoate & 14 & Fruity, grass & 3.76 & 0.88 & 0.15 \\
\hline 5 & Ethyl butanoate & 11 & Fruity, overripe cashew & 2.73 & 0.52 & 0.17 \\
\hline 7 & Ethyl 2-methylbutanoate & 14 & Fruity, cashew, sweet & 4.68 & 1.76 & 0.97 \\
\hline 9 & Ethyl 3-methylbutanoate & 14 & Cashew apple, sweet & 4.21 & 1.58 & 3.31 \\
\hline 13 & Isoamyl acetate & 6 & Enamel, fruity, banana & 1.72 & 0.43 & 0.05 \\
\hline 15 & Ethyl trans-2-butenoate & 14 & Fruity, cashew apple, flower & 4.72 & 1.81 & 0.04 \\
\hline 16 & Ethyl 3-methylpentanoate & 7 & Fruity, grass, cashew apple & 1.55 & 0.53 & 0.04 \\
\hline 17 & Methyl 2-ethylacrylate & 11 & Beetle, grass, sweet, flower & 4.15 & 1.36 & $\operatorname{tr}$ \\
\hline 21 & Ethyl trans-3-hexenoate & 5 & Fruity, flower, cashew apple & 0.95 & 0.12 & 0.05 \\
\hline 24 & Ethyl trans-2-hexenoate & 4 & Fruity, sweet & 0.69 & 0.12 & 0.09 \\
\hline 29 & Ethyl 3-hydroxy-3-methylbutanoate & 5 & Fruity, grass, grain, cashew & 1.34 & 0.32 & 0.24 \\
\hline 31 & Ethyl octanoate & 14 & Grain, wet ground, butter & 4.08 & 1.47 & $\operatorname{tr}$ \\
\hline 35 & Methyl 2-hydroxy-3-methylpentanoate & 13 & Fruity, guava, citric, flower & 3.61 & 1.38 & 0.03 \\
\hline 38 & Methyl 2-hydroxy-4-methylpentanoate & 11 & Fruity, grass, cashew & 2.52 & 0.74 & 0.34 \\
\hline 39 & Ethyl 2-hydroxy-4-methylpentanoate & 5 & Fruity, lemon & 1.38 & 0.29 & 13.97 \\
\hline 41 & Ethyl 2-hydroxyhexanoate & 15 & Cashew, 'pitanga' & 6.63 & 5.29 & 0.12 \\
\hline 43 & Ethyl decanoate & 6 & Cashew, flower, grass & 1.68 & 2.69 & $\operatorname{tr}$ \\
\hline \multirow[t]{2}{*}{46} & Ethyl 3-hydroxyhexanoate & 5 & Grass, fruity & 1.16 & 1.38 & 0.04 \\
\hline & Alcohol & & & & 17.17 & 36.53 \\
\hline 6 & 2-2-Methyl-3-buten-2-ol & 10 & Fruity, cooked pineapple & 3.00 & 0.87 & 0.29 \\
\hline 12 & 2-Methyl-1-propanol & 8 & Grass, grain & 2.39 & 0.52 & 1.62 \\
\hline 19 & 3-Methyl-1-butanol & 11 & Overripe cashew & 5.00 & 1.40 & 24.03 \\
\hline 22 & Trans-2-Penten-1-ol & 5 & Grass, mould, fermented & 1.09 & 0.18 & 0.10 \\
\hline 23 & 4-Methyl-1-pentanol & 7 & Grass, herb, green fruity & 1.50 & 0.47 & 0.29 \\
\hline 25 & Hexanol & 5 & Grass, sweet, almond oil & 1.54 & 0.47 & 4.11 \\
\hline 26 & Trans-3-Hexen-1-ol & 15 & Grass, fruity, perfume, floral & 5.43 & 2.68 & 0.94 \\
\hline 28 & cis-3-Hexen-1-ol & 10 & Grass, sweet, fruity & 4.31 & 1.50 & 4.52 \\
\hline 34 & Heptanol & 13 & Cashew, fruity, grass & 5.63 & 2.85 & 0.14 \\
\hline 36 & 2-Ethyl-1-hexanol & 10 & Grass, herb, floral & 4.29 & 2.18 & 0.10 \\
\hline \multirow[t]{2}{*}{40} & 1-Octanol & 14 & Floral, fruity, grass & 4.56 & 4.05 & 0.39 \\
\hline & Aldehyde & & & & 6.38 & 1.94 \\
\hline 10 & Hexanal & 11 & Grass, herb & 3.03 & 1.04 & 0.11 \\
\hline 14 & 2-Methyl-4-pentenal & 15 & Grass, fruity, sweet & 5.81 & 2.90 & 0.12 \\
\hline 18 & Trans-2-Hexenal & 11 & Pentatomidae bug, grass & 4.42 & 2.22 & 1.54 \\
\hline \multirow[t]{2}{*}{33} & Furaldehyde & 7 & Wood, coconut, unpleasant & 1.24 & 0.22 & 0.17 \\
\hline & Ketone/lactone & & & & 9.77 & 12.88 \\
\hline 3 & 2,3-Butanedione & 13 & Fermented, cashew, sweet & 3.39 & 0.98 & 3.30 \\
\hline 8 & 2,3-Pentanedione & 11 & Fruity, cashew, fermented & 3.30 & 1.19 & 0.07 \\
\hline 20 & 3-Hydroxy-2-butanone & 8 & Fruity, herb & 2.47 & 0.76 & 7.08 \\
\hline 42 & Acetophenone & 13 & Cheese, acid, sweet, wax & 6.81 & 2.93 & 0.38 \\
\hline \multirow[t]{2}{*}{49} & $\gamma$-Dodecalactone & 8 & Cashew, wine, herb & 3.06 & 3.91 & 2.05 \\
\hline & Acid & & & & 35.43 & 12.32 \\
\hline 32 & Acetic acid & 15 & Cooked pineapple, medicine & 6.95 & 4.27 & $\operatorname{tr}$ \\
\hline 44 & 3-Methylbutanoic acid + & 15 & Cheese, foot odour & 9.23 & 26.72 & 11.63 \\
\hline 45 & 2-methylbutanoic acid & & & & & \\
\hline 47 & Hexanoic acid & 4 & Cashew, sweet, grass & 0.57 & 0.31 & 0.34 \\
\hline 48 & Nonanoic acid & 4 & Sweet, fruity & 0.86 & 0.38 & 0.08 \\
\hline 49 & Decanoic acid & 7 & Floral, grass, citric & 1.95 & 2.28 & 0.27 \\
\hline \multirow[t]{2}{*}{52} & Phenylacetic acid & 4 & Woody, overripe cashew & 1.42 & 1.47 & $\operatorname{tr}$ \\
\hline & Compounds not detected by the FID or not identified by GC-MS & & & & 5.23 & 5.09 \\
\hline 11 & Peak 11 ND & 6 & 'Cajuina', grain & 1.90 & 0.61 & - \\
\hline 27 & Peak 27 NI & 11 & Grass & 3.73 & 1.87 & 1.05 \\
\hline
\end{tabular}


Table 4. (Continued)

\begin{tabular}{|c|c|c|c|c|c|c|}
\hline Peak & Compound & Freq $^{\text {a }}$ & Descriptor $^{b}$ & $I_{\max }{ }^{c}$ & $\% A_{\text {Osme }}{ }^{d}$ & $\% A_{\mathrm{FID}}{ }^{\mathrm{e}}$ \\
\hline 30 & Peak $30 \mathrm{NI}$ & 5 & Fruity, cashew, sweet, floral & 1.17 & 0.36 & $\operatorname{tr}$ \\
\hline 37 & Peak $37 \mathrm{NI}$ & 6 & Plastic, wood, grain & 1.38 & 0.42 & 2.85 \\
\hline 51 & Peak $50 \mathrm{NI}$ & 7 & Grain, beer, cashew & 2.29 & 1.97 & 1.19 \\
\hline \multicolumn{7}{|c|}{$\begin{array}{l}\text { a Frequency: number of times that each volatile was perceived in the GC effl } \\
\text { b Descriptors: main descriptors generated by the judges. } \\
\text { c Average intensity at the consensual Osmegram ( } 0=\text { none; } 10=\text { extreme). } \\
\text { d Percentage of the total aromagram area. } \\
\text { e Percentage of the total chromatogram area. } \\
\text { ND, not detected by FID; NI, not identified. }\end{array}$} \\
\hline
\end{tabular}

such as pervaporation, could generate a natural cashew apple water phase or essence with greater quality.

\section{ACKNOWLEDGMENTS}

The authors are grateful for the financial support of CNPq, CAPES and the Bank of Interamerican Regional Development (BIRD).

\section{REFERENCES}

1 Karlsson HOE and Trägardh G, Aroma recovery during beverage processing. J Food Eng 34:159-178 (1997).

2 Fisher CF and Scott TR, Food flavours: Biology and Chemistry. Royal Society of Chemistry, Cambridge, UK, pp. 15-55 (1997).

3 Reineccius G, Changes in flavor due to processing, in Flavor Chemistry and Technology, ed. by Reineccius G. Taylor \& Francis, Boca Raton, FL, pp. 103-137 (2006).

4 Macleod AJ and Troconis NG, Volatile flavour components of cashew apple (Anacardium occidentale). Phytochemistry 21:2527-2530 (1982).

5 Maciel MI, Hansen TJ, Aldinger SB and Labows JN, Flavor chemistry of cashew apple juice. J Agric Food Chem 34:923-927 (1986).

6 Maia JGS Andrade EHA and Zoghbi MGB, Volatile constituents of the leaves, fruits and flowers of cashew (Anacardium occidentale $\mathrm{L}$ ). J Food Compos Anal 13:277-232 (2000).

7 Bicalho B, Pereira AS, Aquino Neto FR, Pinto AC and Rezende CM, Application of high-temperature gas chromatography-mass spectrometry to the investigation of glycosidically bound components related to cashew apple (Anacardium occidentale L. Var nanum) volatiles. J Agric Food Chem 48:1167-1174 (2000).

8 Garruti DS, Franco MRB, Da Silva MAAP, Janzantti NS and Alves GA, Evaluation of volatile flavour compounds from cashew apple (Anacardium occidentale L) juice by Osme gas chromatography/olfactometry technique. J Sci Food Agric 83:1455-1462 (2003).

9 Valim MF, Rouseff RL and Lin J, Gas chromatographic-olfactometric characterization of aroma compounds in two types of cashew apple nectar. J Agric Food Chem 51:1010-1015 (2003).

10 Cardeal ZL, Guimarães EL and Parreira FV, Analysis of volatile compounds in some typical Brazilian fruits and juices by SPME-GC method. Food Addit Contam 22:508-513 (2005).

11 Aroujalian A and Raisi A, Recovery of volatile aroma components from orange juice by pervaporation. J Membr Sci 303:154-161 (2007).

12 Gutterson M, Fruity Juice Technology. Noyes Data Corporation, Park Ridge, NJ, pp. $35-78$ (1970).

13 Chardon S, Quemarais B, Schwartzberg H, lakovidis A and Lazaridis H, Aroma loss and recovery during batch evaporation, in Engineering and Food, Vol. 3, ed. by Spiess WEL and Schubert H. Elsevier, London, pp. 118-127 (1990).

14 Yanniotis S, Tsitziloni K, Dendrinos G and Mallouchos A, Aroma recovery by combining distillation with absorption. J Food Eng 78:882-887 (2007).

15 Bomben JL, Bruin S and Thijssen HAC Aroma recovery and retention in concentration and drying of foods, in Advances in Food Research, ed. by Chichester CO, Mark EM and Stewart GR. Academic Press, New York, pp. 1-52 (1973).
16 Braddock RJ, Handbook of Citrus By-Products and Processing Technology. Wiley, Hoboken, NJ, pp. 149-174 (1999).

17 Redd JB and Hendrix CM Jr, Processing of natural citrus oils and flavors, in Fruit Juice Processing Technology, ed. by Nagy S, Chen CS and Shaw PE. Agscience, Auburndale, FL, pp. 83-109 (1993).

18 Kimball D, Citrus Processing: Quality Control and Technology. Van Nostrand Reinhold, New York, pp. 73-101 (1991).

19 Ramteke RS, Eipeson WE and Patwardhan MV, Behaviour of aroma volatiles during the evaporative concentration of some tropical fruit juices and pulps. J Sci Food Agric 50:399-405 (1990).

20 Sulc $D$, Fruchtsaftkonzentrierung und fruchtaromaseparierung. Confruta Studien 28:258-318 (1984).

21 Soni V, Abildskov J, Jonsson G and Gani R, Modeling and analysis of vacuum membrane distillation for the recovery of volatile aroma compounds from black currant juice. J Membr Sci 320:442-455 (2008).

22 Cassano A, Figoli A, Tagarelli A, Sindona G and Drioli E, Integrated membrane process for the production of highly nutritional kiwifruit juice. Desalination 189:21-30 (2006).

23 Pereira CC, Ribeiro CP Jr, Nóbrega R and Borges CP, Volatile aroma compounds from fruit juices. J Membr Sci 274:1-23 (2006).

24 Olsson J and Trägardh G, Influence of feed flow velocity on pervaporative aroma recovery from a model solution of apple juice aroma compounds. J Food Eng 39:107-115 (1999).

25 IBRAF (Instituto Brasileiro de Frutas), Estatísticas. [Online]. Available: http://www.ibraf.org.br [15 March 2009].

26 Rosa SES Cosenza JP and Leão LTS, Panorama do setor de bebidas no Brasil. BNDES Setorial 23:101-150 (2006). http://www.bndes. gov.br/conhecimento/bnset/set2304.pdf [22 April 2008].

27 Abecitrus (Associação Brasileira dos Exportadores de Cítricos). [Online]. Available: http://www.abecitrus.com.br [15 March 2009].

28 Oliveira $\mathrm{VH}$, Influência da irrigação na produção de pedúnculo e de castanha em clones de cajueiro-anão-precoce. Rev Bras Frutic 24:717-720 (2002).

29 IBGE (Instituto Brasileiro de Geografia e Estatística). [Online]. Available: http://www.sidra.ibge.gov.br/bda/prevsaf [15 June 2010].

30 EMBRAPA (Empresa Brasileira de Pesquisa Agropecuária), Cultivo do cajueiro (January2003). [Online]. Available: http://sistemasdeproducao.cnptia.embrapa.br/FontesHTML/Caju/CultivodoCajuei ro/index.htm [15 June 2010].

31 Damásio $\mathrm{MH}$ and Costell E, Análisis sensorial descriptivo: generación de descriptores y selección de catadores. Rev Agroquim Tecnol 31:165-178 (1991).

32 American Society for Testing and Materials, Guidelines for the selection and training of sensory panel members (ASTM Special Technical Publication No. 758), Philadelphia (1981).

33 Wolford RW, Alberding GE and Attaway JA, Analysis of recovered natural orange essence by gas chromatography. J Agric Food Chem 10:297-301 (1962).

34 Van Den Dool H and Kratz PD, A generalization of the retention index system including linear temperature programmed gas-liquid partition chromatography. J Chromatogr 11:463-471 (1963).

35 Jennings WG and Shibamoto T, Qualitative Analysis of Flavor and Fragrance Volatiles by Glass Capillary Gas Chromatography. Academic Press, San Francisco, CA (1985).

36 Acree TE and Arn H, Flavornet-gas chromatography-olfactometry (CGO) of natural products. [Online]. Available: http://www.nysaes. cornell.edu/flavornet [18 January 2007]. 
37 CarasekE and Pawliszyn J, Screening of tropical fruit volatile compounds using solid-phase microextraction (SPME) fibers and internally cooled SPME fiber. J Agric Food Chem 54:8688-8696 (2006).

38 Jordán MJ, Margaría CA, Shaw PE and Goodner KL, Volatile components and aroma active compounds in aqueous essence and fresh pink guava fruit puree (Psidium guajava L.) by GC-MS and multidimensional GC/GC-O. J Agric Food Chem 51:1421-1426 (2003).

39 Jordán MJ, Goodner KL and Shaw PE, Characterization of the aromatic profile in aqueous essence and fruit juice of yellow passion fruit (Passiflora edulis Sims F. Flavicarpa degner) by GC-MS and GC/O. J Agric Food Chem 50:1523-1528 (2002).
40 Jordán MJ, Tandon K, Shaw PE and Goodner KL, Aromatic profile of aqueous banana essence and banana fruit by gas chromatography-mass spectrometry (GC-MS) and gas chromatography-olfactometry (GC-O). J Agric Food Chem 49:4813-4817 (2001).

41 Jordán MJ, Margaría CA, Shaw PE and Goodner KL, Aroma active components in aqueous kiwi fruit essence and kiwi fruit puree by GC-MS and multidimensional GC/GC-O. J Agric Food Chem 50:5386-5390 (2002).

42 Ducruet V, Fournier N, Saillard P, Feigenbaum A and Guichard E, Influence of packaging on the aroma stability of strawberry syrup during shelf life. J Agric Food Chem 49:2290-2297 (2001). 